\title{
UTILIZAÇÃO DO REJEITO DO PROCESSO BAYER COMO MATÉRIA-PRIMA NA PRODUÇÃO DE AGREGADOS LEVES
}

\author{
D. H. dos SANTOS $^{1}$, A. P. DALMEIDA ${ }^{1}$, W. B. FIGUEIREDO ${ }^{1}$, A. L. Valente $^{1}$, J. A. S. \\ SOUZA $^{1}$ \\ ${ }^{1}$ Universidade Federal do Pará, Faculdade de Engenharia Química \\ Email para contato: diegohildebrando@gmail.com
}

RESUMO - A utilização de resíduos da indústria de mineração e metalurgia tornou-se indispensável para que este segmento industrial insira-se no conceito de desenvolvimento sustentado, passando a priorizar definitivamente o meio ambiente, contribuindo efetivamente para programas de preservação. Este trabalho mostra uma interessante aplicação, para o resíduo proveniente do processo de produção de alumina metalúrgica (Processo Bayer), a lama vermelha gerada em grande quantidade cerca de 1,2 ton/ton de alumina. O trabalho mostra a aplicação da lama vermelha, que misturada com outros materiais como sílica e argila produz um material com resistência mecânica e densidade, que pode ser comparada aos agregados naturais utilizados pela indústria de construção civil. Este material sintético é capaz de substituir alguns agregados como o seixo rolado e a brita, com a vantagem de não precisar ser extraído da natureza, contribuindo para a preservação ambiental e consumindo o passivo armazenado pela indústria de alumina.

\section{INTRODUÇÃO}

Nas indústrias de beneficiamento de alumina, como a HYDRO ALUNORTE, como em qualquer outra indústria, há uma grande geração de quantidade de resíduos que ocasionam impactos ambientais, tal resíduo é conhecido comumente como lama vermelha (red mud), material insolúvel que surge após a digestão da bauxita pelas soluções de hidróxido de sódio, na fabricação de alumina pelo processo Bayer. A lama vermelha não possui valor comercial, daí o estudo para amenizar seu impacto ambiental e sua valorização econômica. Além disso, deve-se destacar que a utilização desse rejeito tende a minimizar os problemas ambientais, pois o mesmo tem como principal característica uma elevada alcalinidade ( $\mathrm{pH} \mathrm{10-13)} \mathrm{e}$ elevados custos, pois como o mesmo é armazenado em depósitos de rejeitos a céu aberto, necessitando dispor de grandes áreas para esses depósitos.

A proposta deste trabalho é de dar um novo destino a esse resíduo do processo Bayer e por possuir elevadas concentrações de óxidos como o de ferro e de hidróxido de sódio facilita o processo de sinterização na fabricação de agregados sintéticos, que podem possuir características físico-químicas importantes facilitando assim, a substituição dos agregados retirados da natureza que são utilizados na construção civil. O objetivo principal é a produção 
de um material cerâmico, conhecido como agregado leve (por possuir valor de massa específica menor que $2 \mathrm{~g} / \mathrm{cm} 3$ ).

Para a preparação dos materiais cerâmicos, inclusive para a preparação de agregado leve, é necessário a utilização, além da lama vermelha, de outros materiais como a argila e a sílica, pois estes materiais possuem propriedades importantes na preparação das misturas como dureza e plasticidade. Devido a essa exigência é que foi desenvolvida a mistura lama vermelha - sílica para a produção de agregado leve a partir desse rejeito, o presente trabalho pretende contribuir com o desenvolvimento de tecnologias que permitam mostrar os métodos de elaboração e a utilização do agregado leve a partir da lama vermelha.

\section{MATERIAIS E MÉTODOS}

A lama vermelha (resíduo do Processo Bayer) e a cinza, utilizadas neste trabalho, foi gentilmente cedida pela HYDRO ALUNORTE (Alumina do Norte do Brasil S/A) que está localizada a $40 \mathrm{~km}$ de Belém no Município de Barcarena-PA. Após o recebimento da lama vermelha, a mesma foi previamente seca a $100^{\circ} \mathrm{C}$ em estufa com recirculação de ar durante $24 \mathrm{~h}$ e posteriormente moída em moinho de bolas por um período de 30 minutos para promover diminuição das partículas do material. A argila retirada das margens do rio Guamá recebeu o mesmo pré-tratamento realizado para a Lama Vermelha. A areia utilizada foi a mesma que é comercializada na região e peneirada em uma peneira de $149 \mu \mathrm{m}(100$ mesh). A biomassa utilizada para produção dos agregados foi o carvão vegetal (expansão do material). Este carvão chegou a usina de materiais e foi submetido a moagem durante um tempo de 30 minutos. Posteriormente todo carvão foi peneirado e tudo que ficou abaixo de 65 mesh foi utilizado na mistura dos corpos de prova. Após a mistura das matérias-primas em moinho de bolas para promover a homogeneização dos materiais durante 30 minutos, a mistura foi colocada em uma betoneira onde os corpos de prova (pelotas) foram produzidos. Com a movimentação da betoneira as pelotas eram formadas com adição de água de forma gradativa e apresentaram tamanhos variados, de acordo com a Figura 1. A seguir a tabela 1 mostrará as porcentagens de cada matéria-prima na composição dos corpos de prova.

Tabela 1 - Composição percentual das matérias-primas

\begin{tabular}{ccccc}
\hline AMostras & $\begin{array}{c}\text { Lama Vermelha } \\
(\%)\end{array}$ & $\begin{array}{c}\text { SílICA } \\
(\%)\end{array}$ & $\begin{array}{c}\text { ARGILA } \\
(\%)\end{array}$ & $\begin{array}{c}\text { BIOMASSA } \\
(\%)\end{array}$ \\
\hline M-10 & 55 & 25 & 10 & 10 \\
$M-15$ & 50 & 25 & 10 & 15 \\
$M-20$ & 45 & 25 & 10 & 20 \\
$M-25$ & 40 & 25 & 10 & 25 \\
$M-30$ & 35 & 25 & 10 & 30 \\
\hline
\end{tabular}




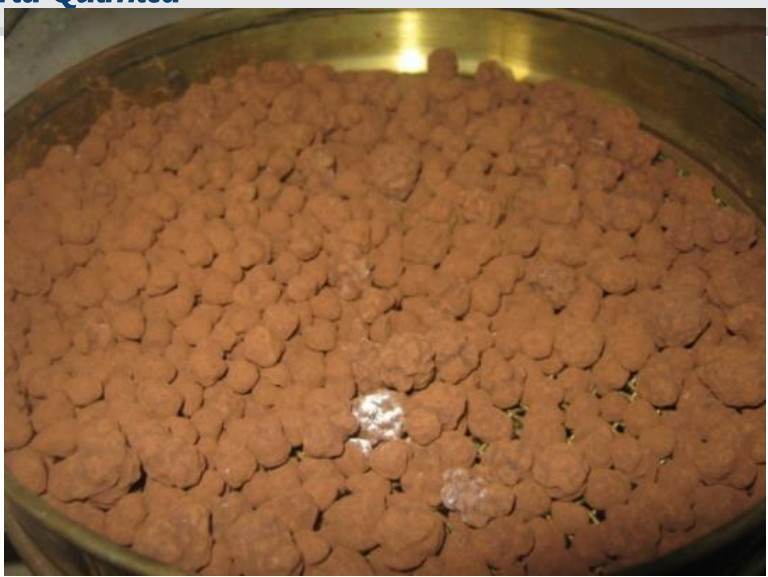

Figura 1- Pelotas formadas dentro da betoneira

Em seguida, os corpos de prova foram colocados em estufa na temperatura de $100{ }^{\circ} \mathrm{C}$ durante $24 \mathrm{~h}$ e após secagem sinterizados a $1300^{\circ} \mathrm{C}$, durante 3 horas. $\mathrm{O}$ aspecto do material sinterizado pode ser observado na Figura 2 a seguir.

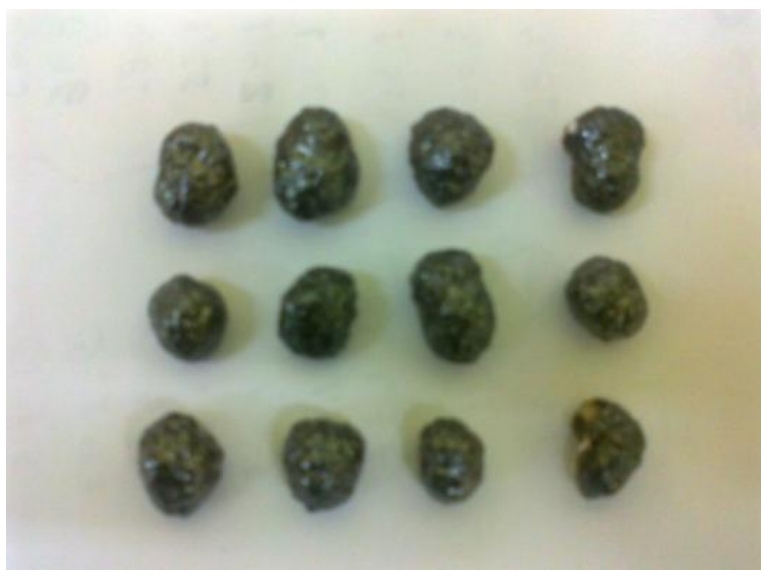

Figura 2- Corpos de prova sinterizados

Após a sinterização dos corpos foram realizados os ensaios cerâmicos para a determinação de Porosidade Aparente, Absorção de Água e Massa Especifica Aparente, conforme as Equações (1), (2) e (3), respectivamente. O método adotado para medir tais propriedades foi citado por (SANTOS, 1989 e ASTM, 1984).

$$
\begin{aligned}
& P A(\%)=\frac{M_{u}-M_{S}}{M_{u}-M_{i}} \times 100 \quad A A(\%)=\frac{M_{u}-M_{s}}{M_{s}} \times 100 \quad \operatorname{MEA}\left(\mathrm{g} / \mathrm{cm}^{3}\right)=\frac{M_{s}}{M_{u}-M_{i}} \\
& \text { Equação (1) } \\
& \text { Equação (2) } \\
& \text { Equação (3) }
\end{aligned}
$$

Os ensaios cerâmicos foram realizados da seguinte forma: Após sinterização dos corpos de prova os mesmos foram pesados determinando-se a massa de sólido seco. Em seguida os corpos de prova foram submergidos em um recipiente contendo água por 24 horas. Após este período, foi determinada a massa úmida. Em seguida, colocou-se a balança em um aparato de madeira acoplado a uma haste de aço, para obter a massa imersa, uma vez que este está 
submerso em um recipiente com água suficiente para cobrir o corpo de prova, como podemos ver na figura 3.

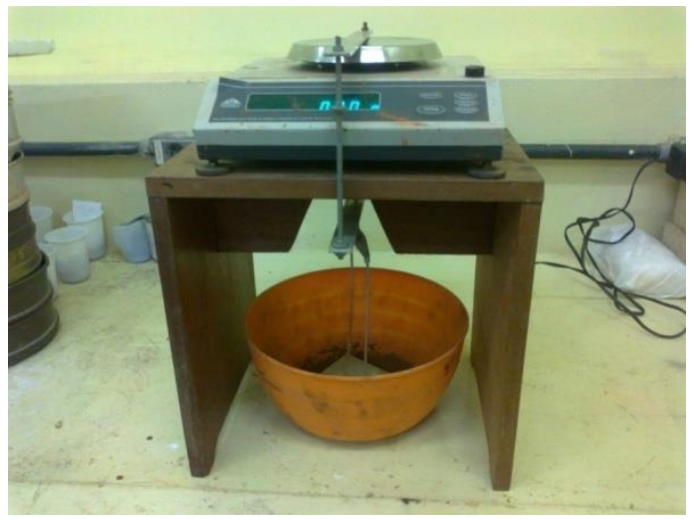

Figura 3 - Mostrando o suporte de madeira e a haste onde foi feito o peso imerso

A característica principal para ser considerado agregado leve, o material produzido precisará ter uma massa específica inferior a $2 \mathrm{~g} / \mathrm{cm}^{3}$.

\section{RESULTADOS E DISCUSSÃO}

Observa-se na Tabela 2 a composição química (fluorescência de raios-x) da Lama Vermelha que apresenta como componentes majoritários o óxido de ferro, silício e aluminio. Os compostos de silício e a alumina quando sinterizados a uma temperatura de $1300^{\circ} \mathrm{C}$ reagem formando mulita secundária, composto estável, que da característica de resistência ao material.

\begin{tabular}{cc} 
Tabela 2 - Composição química da lama vermelha \\
\hline Constituintes da lama vermelha & $(\%)$ peso \\
\hline $\mathrm{Fe} 2 \mathrm{O} 3$ & 29,538 \\
$\mathrm{SiO} 2$ & 17,283 \\
$\mathrm{CaO}$ & 1,082 \\
$\mathrm{Al} 2 \mathrm{O} 3$ & 22,539 \\
$\mathrm{TiO} 2$ & 4,56 \\
$\mathrm{Na} 2 \mathrm{O}$ & 12,508 \\
$\mathrm{~V} 2 \mathrm{O} 5$ & 0,28 \\
$\mathrm{MgO}$ & 0,148 \\
$\mathrm{~K} 2 \mathrm{O}$ & 0,027 \\
P.F. (perda ao fogo) & 12,035 \\
\hline
\end{tabular}


Os resultados apresentados na Tabela 3 revelam que com a diminuição do teor de Lama Vermelha e consequente aumento do teor de cinza, proporciona um aumento da massa específica aparente e diminuição da porosidade aparente e absorção de água. Desta forma podemos observar que essas propriedades apresentam um comportamento inversamente proporcional, caracterizado pelo aumento da quantidade de fundente presente na Cinza, fazendo com que a fase amorfa, constituída principalmente da camada vítrea que compõem o agregado, torne-se mais espessa diminuindo a quantidade de poros, causando assim um decréscimo na absorção de água que é uma medida indireta da porosidade.

Tabela 3 - Resultados da massa específica, porosidade e absorção de água

\begin{tabular}{llll}
\hline MISTURAS & MEA(g/cm3) & PA(\%) & AA(\%) \\
\hline M-10 & 1,4513 & 4,04 & 2,77 \\
M-20 & 1,3976 & 4,65 & 3,52 \\
M-30 & 1,3550 & 5,34 & 4,77 \\
M-40 & 1,4015 & 4,75 & 2,84 \\
M-50 & 1,5413 & 3,73 & 2,25 \\
\hline
\end{tabular}

Com os resultados mostrados na tabela 3 pode-se perceber que quando aumenta-se o teor de biomassa (carvão) presente nas amostras de M-10 a M-30, verifica-se que sua massa específica aparente diminui até a mistura contendo $20 \%$ de biomassa e a partir desse valor a MEA aumenta. Isso acontece, pois quanto maior for o teor de biomassa, maior será a expansão ocorrida no interior do agregado e assim menor será sua massa específica aparente (MEA). Porém ao utilizar uma quantidade com teores acima de $20 \%$ de biomassa é observado que a massa específica aparente aumenta devido uma dissolução da mulita,fato esse ocasionado pelo aumento de temperatura no interior do agregado, essa elevada temperatura está relacionada com os teores elevados da biomassa. Pode-se ver também que os valores da amostra M-15 (MEA=1,39 g/cm3) e amostra M-25 (MEA= 1,40 g/cm3) são ligeiramente parecidos, entretanto a amostra com um maior teor de biomassa deverá possuir uma resistência muito pequena em relação a amostra M-15, pois para essas amostras (M-25) como a temperatura foi alta, a mulita, composto importante no que se diz respeito a resistência do agregado, prejudicando assim a resistência do material.

Os dados obtidos mostram que a porosidade aumenta com o aumento da concentração de biomassa na mistura até $20 \%$ de biomassa para a temperatura de $1300{ }^{\circ} \mathrm{C}$. Para teores mais elevados de biomassa, há uma tendência a diminuição da porosidade. Este fato está relacionado com o aumento da fase vítrea. A redução da porosidade é responsável pelo aumento da massa específica. Apesar dos valores de porosidade entre as amostras M-15 e M25 serem relativamente parecidos.

O comportamento da absorção de água em relação ao aumento do teor de biomassa no agregado ocorre de uma forma que até uma concentração de $20 \%$ a absorção de água se comporta de forma crescente devido ao fato de que nesta faixa de concentração a porosidade 
aparente também aumenta, porém pode ser observado que a partir de uma concentração de biomassa de $20 \%$ a absorção de água diminui devido ao fato da porosidade aparente se comportar de forma decrescente nesta faixa de concentração.

\section{ANÁLISE DE DIFRAÇÃO DE RAIOS-X}

Pela a análise de difratometria de raios-x podemos observar que os picos da Mulita e da sílica aparecem muito próximos um do outro. De acordo com as duas análises dos raios-X podemos verificar que quando a porcentagem de biomassa é igual a $20 \%$ o pico característico da mulita com a sílica (na forma de quartzo) está bem definido. Mas com o decorrer do aumento do teor de biomassa de cada amostra, a mulita vai sendo redissolvida pelo material, ocasionado pelo aumento da temperatura interna do agregado, chegando ao ponto de na análise com a amostra M-30, este pico de mulita não poder ser mais observado.

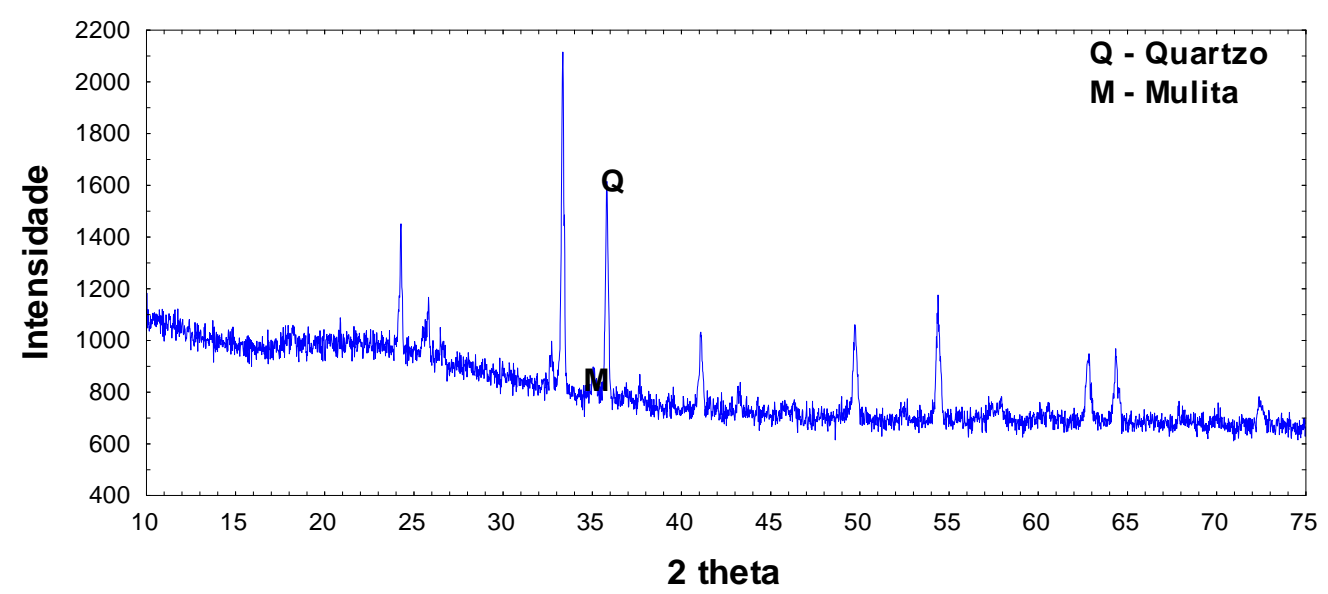

Figura 4 - Difração de raio-x da amostra M-20

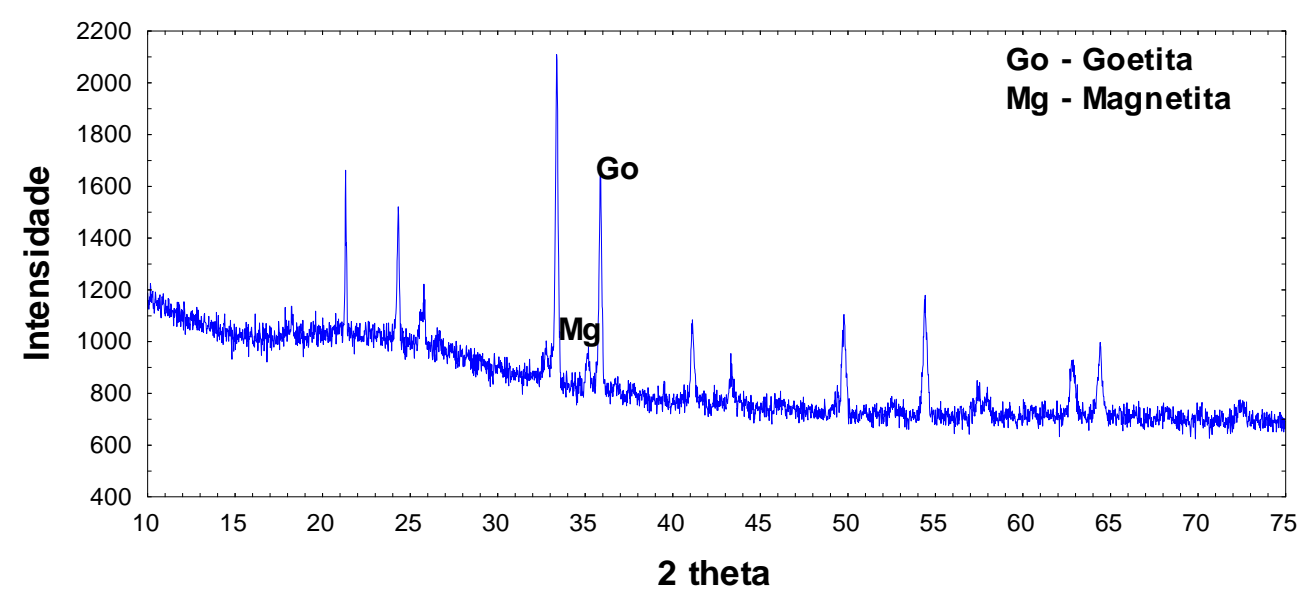

Figura 5 - Difração de raio-x da amostra M-30 


\section{RESISTÊNCIA MECÂNICA A COMPRESSÃO}

Para o comportamento a ensaio de compressão, foram fabricados corpos de prova para ensaios em concreto utilizando uma relação agregado / cimento 4:1 e uma relação agua/cimento de 0,85 de acordo com as normas vigentes. Para avaliação da resistência a compressão no concreto, foi utilizado o agregado fabricado com $25 \%$ de sílica e $10 \%$ de biomassa, variando a temperatura de sinterização, como mostra a tabela 5

Tabela 4. Comportamento da resistência à compressão do concreto fabricado com agregado sintético.

\begin{tabular}{cccc}
\hline Amostra & $\begin{array}{c}\text { Massa } \\
\text { específica } \\
\left(\mathrm{g} / \mathrm{cm}^{3}\right)\end{array}$ & $\begin{array}{c}\text { Porosidade } \\
(\% \text { volume })\end{array}$ & $\begin{array}{c}\text { Resistência à } \\
\text { compressão } \\
(\mathrm{MPa})\end{array}$ \\
\hline $\begin{array}{c}\text { Concreto produzido com lama } \\
\text { vermelha e 20\% sílica }-1200^{\circ} \mathrm{C}\end{array}$ & 2,72 & 1,78 & 40,34 \\
$\quad \begin{array}{c}\text { Concreto produzido com lama } \\
\text { vermelha e 20\% sílica }-1250^{\circ} \mathrm{C}\end{array}$ & 1,59 & 2,53 & 25,56 \\
$\quad \begin{array}{c}\text { Concreto produzido com lama } \\
\text { vermelha e 20\% sílica }-1300^{\circ} \mathrm{C} \\
\quad \text { Concreto produzido com lama }\end{array}$ & 1,15 & 9,51 & 18,34 \\
vermelha e 20\% sílica $-1350^{\circ} \mathrm{C}$ & 0,92 & 12,30 & 15,65 \\
\hline
\end{tabular}

O teor de sílica pode influenciar diretamente na resistência mecânica do agregado e consequentemente no concreto produzido, como pode ser observado na Tabela 7 , a resistência à compressão do concreto, fabricado com o agregado sintético produzido a $1200^{\circ} \mathrm{C}$, é mais elevada para agregados com maior massa específica. Isto deixa claro que para este caso, que o controle da massa específica, pode ser um parâmetro importante para prever a resistência à compressão do concreto correspondente. Pode-se afirmar também que o aumento na massa específica do agregado, principalmente para o agregado queimado a $1200^{\circ} \mathrm{C}$, implica sempre em um aumento na resistência do concreto fabricado com o mesmo, como pode ser observado no gráfico 6. Desta forma é possível relacionar variáveis como: teor de sílica, temperatura de sinterização com a massa específica do agregado sinterizado e, consequentemente, com a resistência à compressão do concreto fabricado com este agregado. É possível ainda através do controle destas variáveis a produção de diferentes tipos de concreto para diversas aplicações. Desde concretos para alta resistência, como concreto denso, até concreto leve com massa específica menor que $1,5 \mathrm{t} / \mathrm{m} 3$ 


\section{CONCLUSÃO}

- A utilização da lama vermelha como matéria prima para produção de agregado leve possibilita uma boa alternativa na produção deste material, sobretudo por se tratar de uma rejeito de baixo custo e gerado em grande quantidade.

- Todos as amostras tiveram um resultado que fica classificado dentro do que se considera como agregado leve, porém a amostra M-20, com $20 \%$ de biomassa foi a que teve um resultado mais satisfatório apresentando menor valor para a massa específica.

- As amostras que possuem grandes quantidades de biomassa tiveram uma dissolução de mulita e a transformação completa do sílica em vidro pela alta temperatura no interior do agregado, ( as amostras M-25 e M-30 obtiveram valor de massa específica iguais a 1,40g/cm3 e $1,54 \mathrm{~g} / \mathrm{cm} 3$, respectivamente).

- É possível abservar ainda que há uma grande relação entre a porosidade e a resistência do agregado quando utilizado em concreto. Este fato pode ser associado também ao valor de massa especifica, cujo aumento pode estar associado ao aumento da resistência do concreto a compressão.

- Como o uso na construção civil pode ser em grande quantidade, será uma forma de destinar parte da lama vermelha, que é estocada em lagoas e sistemas de contenção, para uso direto, reciclando uma grande quantidade deste material para a fabricação de agregado leve com elevado teor de lama vermelha.

\section{REFERÊNCIAS}

(1) AMARAL, A. S. M. Secagem de materiais extrudados em um secador de convecção forçada utilizando argila do Estado do Pará. 1999.Dissertação (Mestrado em Engenharia Química)- Programa de pós-graduação em Engenharia Química, Belém-PA.

(2) SANTOS, D.H. Utilização do rejeito do processo bayer como matéria-prima na produção de agregados leves. 2011, 73p. Dissertação (Mestrado Profissional em Engenharia Elétrica)-Programa de pós-graduação em engenharia elétrica, Belém-PA.

(3) SANTOS, P. S, Ciência e tecnologia de argilas. 2.ed. EdgardBlücher, 1989. 408 p. v. 1. 